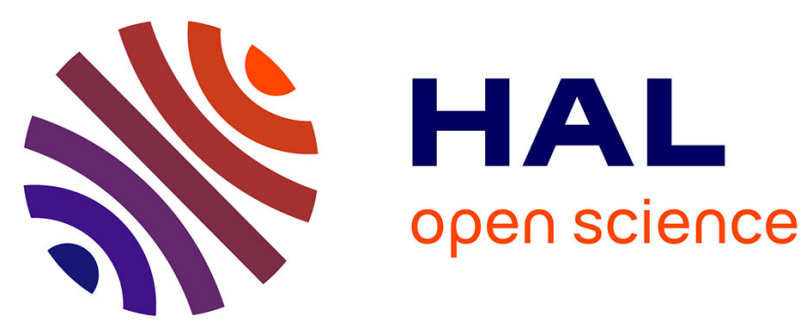

\title{
Time evolution of the depth profile of 113 defects during transient enhanced diffusion in silicon
}

\author{
B. Colombeau, N.E.B. Cowern, Fuccio Cristiano, P. Calvo, Nikolay
}

Cherkashin, Y. Lamrani, Alain Claverie

\section{- To cite this version:}

B. Colombeau, N.E.B. Cowern, Fuccio Cristiano, P. Calvo, Nikolay Cherkashin, et al.. Time evolution of the depth profile of 113 defects during transient enhanced diffusion in silicon. Applied Physics Letters, 2003, 83 (10), pp.1953-1955. 10.1063/1.1608489 . hal-01736110

\section{HAL Id: hal-01736110 \\ https://hal.science/hal-01736110}

Submitted on 27 Mar 2018

HAL is a multi-disciplinary open access archive for the deposit and dissemination of scientific research documents, whether they are published or not. The documents may come from teaching and research institutions in France or abroad, or from public or private research centers.
L'archive ouverte pluridisciplinaire HAL, est destinée au dépôt et à la diffusion de documents scientifiques de niveau recherche, publiés ou non, émanant des établissements d'enseignement et de recherche français ou étrangers, des laboratoires publics ou privés. 


\section{Time evolution of the depth profile of $\{113\}$ defects during transient enhanced diffusion in silicon \\ B. Colombeau, N. E. B. Cowern, F. Cristiano, P. Calvo, N. Cherkashin, Y. Lamrani, and A. Claverie}

Citation: Appl. Phys. Lett. 83, 1953 (2003); doi: 10.1063/1.1608489

View online: https://doi.org/10.1063/1.1608489

View Table of Contents: http://aip.scitation.org/toc/apl/83/10

Published by the American Institute of Physics

\section{Articles you may be interested in}

Microstructural evolution of $\{113\}$ rodlike defects and $\{111\}$ dislocation loops in silicon-implanted silicon Applied Physics Letters 71, 659 (1997); 10.1063/1.119821

Evidences of an intermediate rodlike defect during the transformation of $\{113\}$ defects into dislocation loops Applied Physics Letters 89, 161904 (2006); 10.1063/1.2361178

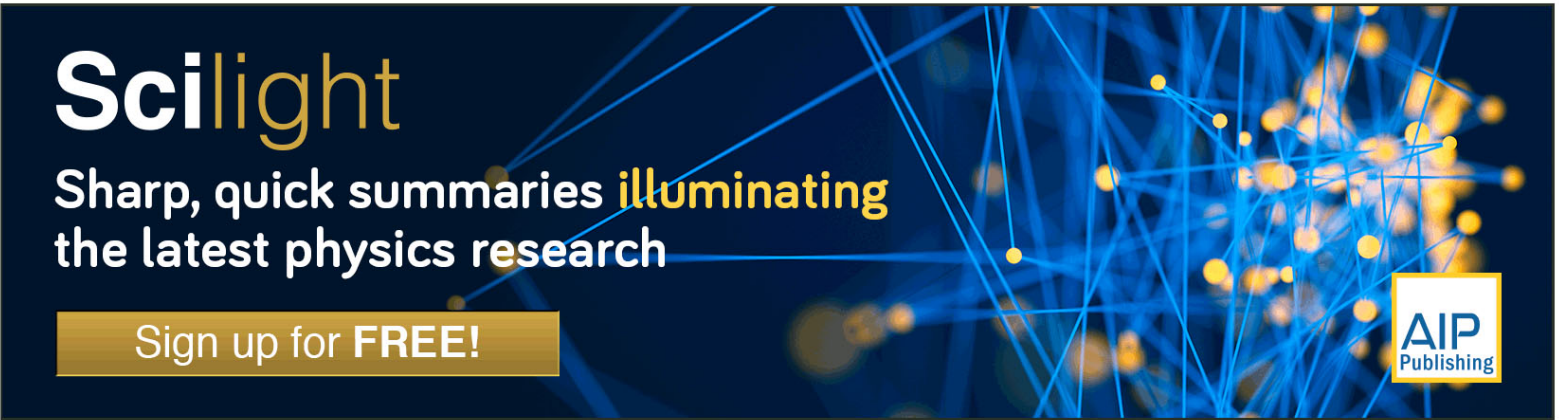




\title{
Time evolution of the depth profile of $\{113\}$ defects during transient enhanced diffusion in silicon
}

\author{
B. Colombeau a) and N. E. B. Cowern \\ Advanced Technology Institute, University of Surrey, Guildford, GU2 7XH, Surrey, United Kingdom \\ F. Cristiano, P. Calvo, N. Cherkashin, Y. Lamrani, and A. Claverie \\ Ion implantation group, CEMES/LAAS-CNRS, Toulouse, France
}

(Received 15 April 2003; accepted 22 July 2003)

\begin{abstract}
The evolution of $\{113\}$ defects as a function of time and depth within Si implant-generated defect profiles has been investigated by transmission electron microscopy. Two cases are considered: one in which the $\{113\}$ defects evolve into dislocation loops, and the other, at lower dose and energy, in which the $\{113\}$ defects grow in size and finally dissolve. The study shows that dissolution occurs preferentially at the near-surface side of the defect band, indicating that the silicon surface is the principal sink for interstitials in this system. The results provide a critical test of the ability of physical models to simulate defect evolution and transient enhanced diffusion. (C) 2003 American Institute of Physics. [DOI: 10.1063/1.1608489]
\end{abstract}

A key issue in modeling and simulation of transient enhanced diffusion (TED) is the way in which implantgenerated extended defects evolve and evaporate during annealing, due to the loss of the self-interstitial atoms which they contain. According to conventional TED models, ${ }^{1-4}$ self-interstitials are lost from extended defects by emission of single interstitial atoms and their subsequent diffusion to other defects (Ostwald ripening) or to the silicon surface (dissolution). This leads to the notion, verified in process simulators, that the defect band should dissolve preferentially on the near-surface side, leading to an increase in mean depth of the band with time. However, it has been reported in recently published transmission electron microscopy (TEM) studies by Moller et al., ${ }^{5}$ that the band of $\{113\}$ defects formed after $\mathrm{Si}$ implantation shows no such asymmetric dissolution. This result has led to considerable controversy in the field, raising the possibility that previous models of point defect transport to the silicon surface are fundamentally incorrect. A resolution of this issue has been an important priority.

In order to get a proper understanding of this phenomenon we have carried out quantitative TEM studies on the depth profile of $\{113\}$ defects. We have studied two cases: $100 \mathrm{keV} 2 \times 10^{14}$ ions $/ \mathrm{cm}^{2} \mathrm{Si}$ implantation, leading to the transformation of $\{113\}$ defects into dislocation loops, and implantation to a somewhat lower energy and dose, $40 \mathrm{keV}$ $6 \times 10^{13}$ ions $/ \mathrm{cm}^{2} \mathrm{Si}$, leading to Ostwald ripening and dissolution of $\{113\}$ defects without transformation into loops.

The Si implants were performed into Si substrates containing lightly doped boron marker layers epitaxially grown by chemical vapor deposition. After implantation, the samples were annealed in nitrogen gas using furnace and/or rapid thermal annealing for various times and temperatures. After processing, plan-view and cross-sectional samples for TEM analysis were prepared by mechanical thinning followed by ion beam milling. Weak beam dark field imaging

${ }^{a)}$ Electronic mail: b.colombeau@surrey.ac.uk conditions were used to measure the size and depth distribution of the extended defects. Cross-sectional (XTEM) images were taken from relatively thick $(\sim 500 \mathrm{~nm})$ and flat regions, in order to keep the uncertainty in the defect density measurements below $15 \%$. The estimation of the specimen thickness was done from Centered Bright/Dark Field images using a (220) reflection. In such imaging conditions the extinction distance, $\xi_{g}$, is $76 \mathrm{~nm}$. Only specimen areas in which the defect band was entirely included within one thickness fringe were selected for the quantitative analysis. The effect of a $15 \%$ defect density variation across the defect band, on the estimated mean depth of the defects, is of the order of $1 \%$.

Considering first the samples implanted at $100 \mathrm{keV} 2$ $\times 10^{14} \mathrm{~cm}^{-2}$, Fig. 1 shows cross-sectional images of the defect distribution as a function of depth after annealing at $850^{\circ} \mathrm{C}$. For short annealing time, the defect band is com-

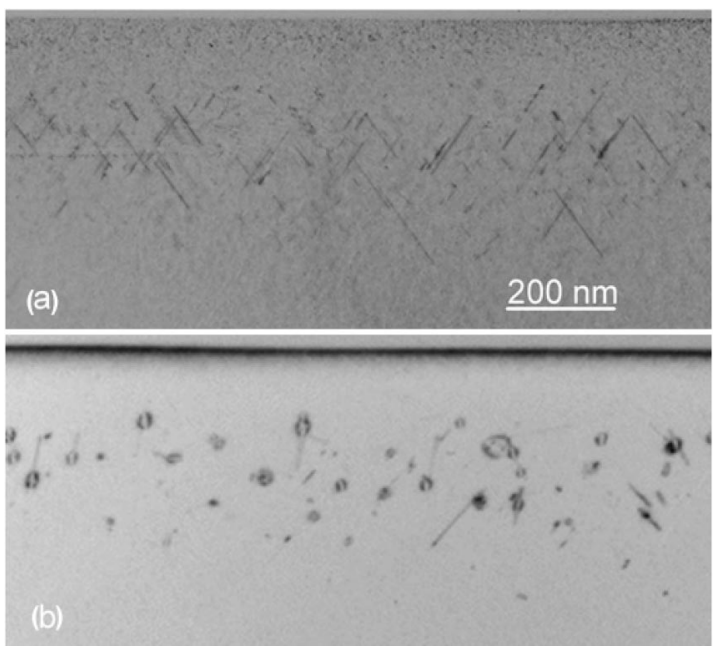

FIG. 1. Cross-sectional images showing the evolution of the defect band after $100 \mathrm{keV}$ Si implantation to a dose of $2 \times 10^{14} \mathrm{~cm}^{-2}$ and annealing at $850^{\circ} \mathrm{C}$. First image (a), after a $30 \mathrm{~s}$ anneal, shows the presence of only $\{113\}$ defects, whilst in the second image (b), after $250 \mathrm{~s}$, both $\{113\}$ defects and dislocation loops can be found. 

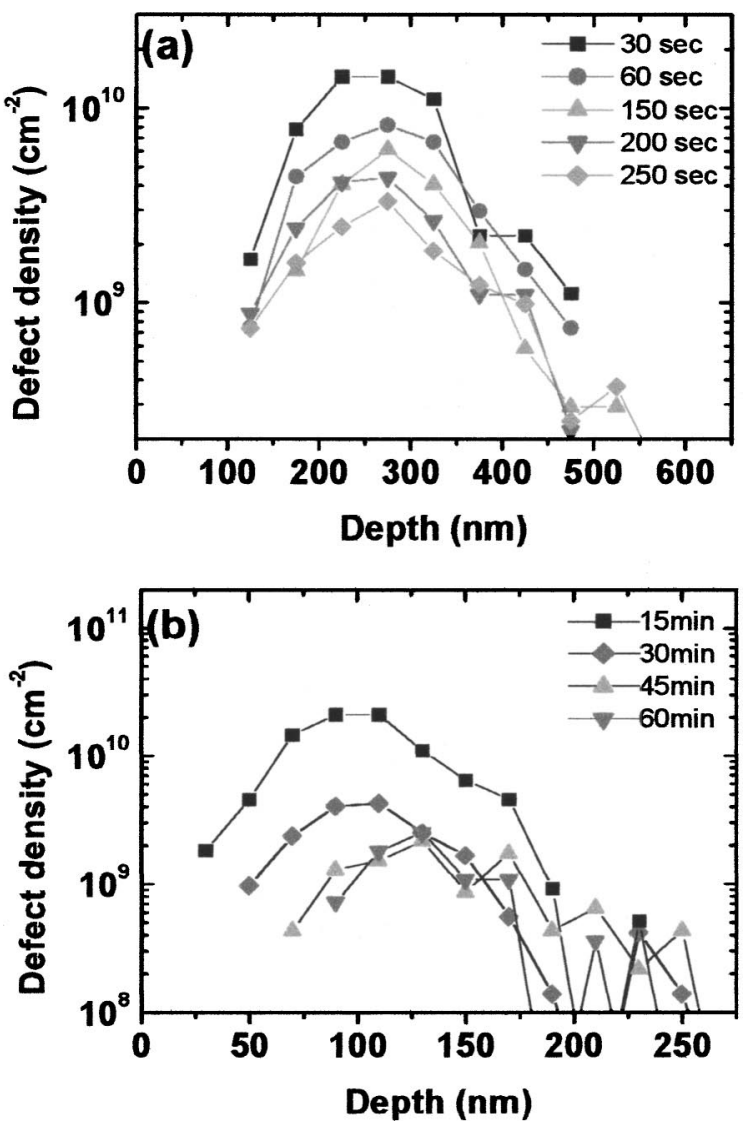

FIG. 2. Time evolution of the defect depth distribution (a) after $100 \mathrm{keV} \mathrm{Si}$ implantation to a dose of $2 \times 10^{14} \mathrm{~cm}^{-2}$ and annealing at $850{ }^{\circ} \mathrm{C}$, and (b) after $40 \mathrm{keV}$ Si implantation to a dose of $6 \times 10^{13} \mathrm{~cm}^{-2}$ and annealing at $740{ }^{\circ} \mathrm{C}$

posed of $\{113\}$ defects while after the longer annealing times, these $\{113\}$ defects have evolved and transformed into dislocation loops. Plan-view analyses (not shown) indicate that, upon annealing, $\{113\}$ defects increase in size and decrease in density before their transformation into dislocation loops, while the number of interstitials contained in the extended defects (total of $\{113\}$ defects plus dislocation loops) decreases only slightly as a function of time. This behavior, involving growth of large stable defects at the expense of smaller less stable ones, without significant dissolution of the defect band as a whole, is typical of a quasiconservative Ostwald ripening process. The key feature of such a process is that the transport of interstitials between the defects is faster than that to external sinks such as the surface. ${ }^{6}$

From cross-sectional extraction, Fig. 2(a) shows the time evolution of the defect depth distribution at $850^{\circ} \mathrm{C}$. Error bars due to specimen thickness variation (discussed earlier) are not reported in the figure, however, they do not affect the following remarks. The defect band remains almost unchanged (in width and peak concentration depth) during annealing, showing only an overall decrease in defect density, an effect which arises from an increase in the size of the defects during annealing. These results are in perfect agreement with the expected defect behavior during a quasiconservative Ostwald ripening process.

For the case of samples implanted at $40 \mathrm{keV} 6$ $\times 10^{13} \mathrm{~cm}^{-2}$, Fig. 3 shows cross-sectional images illustrating the time evolution of the defect distribution as a function

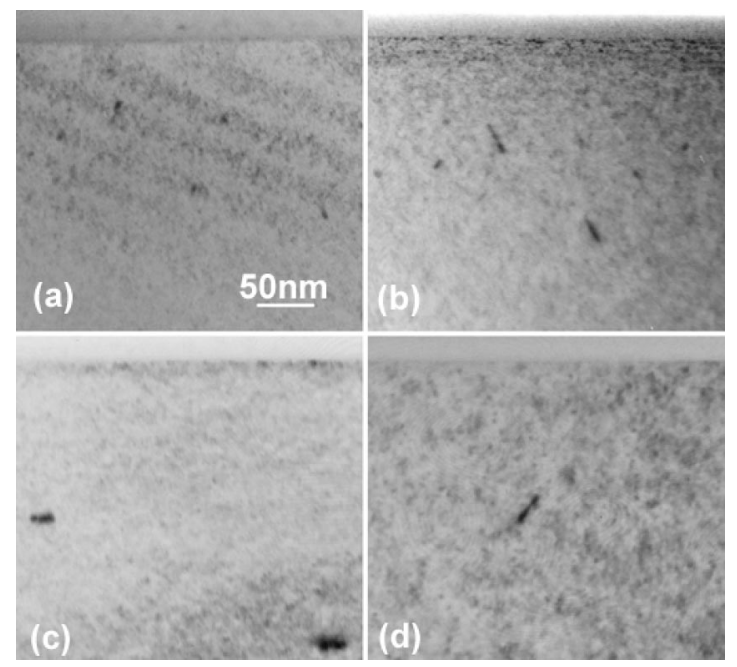

FIG. 3. Cross-sectional images showing the evolution and dissolution of the $\{113\}$ defect band after $40 \mathrm{keV}$ Si implantation to a dose of $6 \times 10^{13} \mathrm{~cm}^{-2}$ and annealing for (a) 15 , (b) 30 , (c) 45 , and (d) $60 \mathrm{~min}$ at $740{ }^{\circ} \mathrm{C}$.

of depth, under conditions where $\{113\}$ defects do not evolve into dislocation loops. The processing conditions were $\mathrm{Si}$ implantation at $40 \mathrm{keV}$ and a dose of $6 \times 10^{13} \mathrm{ions} / \mathrm{cm}^{2}$, followed by annealing at $740{ }^{\circ} \mathrm{C}$ for a range of times. It is immediately apparent that the $\{113\}$ defects both grow and dissolve, since after annealing for 60 min very few $\{113\}$ defects can be detected. Plan-view analysis (not shown) clearly shows that upon annealing the $\{113\}$ defects increase in size and decrease in density until they start to dissolve. As a result of the dissolution, the number of interstitials contained in the defects decreases dramatically with time.

Figure 2(b) presents histograms of the depth distribution of the $\{113\}$ defects during time at $740^{\circ} \mathrm{C}$. In contrast to the stable defect band seen in the previously discussed implant, the $\{113\}$ defect band is found to shrink preferentially on the surface side, while the peak of the distribution moves towards the right (from 100 to $125 \mathrm{~nm}$ ). In contrast to the previous data from Moller et al., it therefore appears that the majority of the interstitials escaping from the defect band originate from near the surface side of the band.

The mean depth of the defects, obtained by integrating the defect density over depth, is shown in Fig. 4. The predominant error in the defect density data arises from sampling statistics. In this case the $1 \sigma$ uncertainty on the mean depth is $w / \sqrt{N}$, where $w$ is the standard deviation of the defect depth profile and $N$ is the number of defects counted. The error bars are $1 \sigma$ values calculated on the assumption that the defect distribution obeys Poisson statistics. In our study the defects are sufficiently large, and their density sufficiently low, those errors in counting and locating the defects in each image can be neglected in comparison to the sampling. During the time frame of the experiments, the mean depth of the defects formed by the $100 \mathrm{keV} 2$ $\times 10^{14} / \mathrm{cm}^{2} \mathrm{Si}$ implant remains constant within the experimental errors. However, the mean depth of the defects formed by the $40 \mathrm{keV} 6 \times 10^{13}$ ions $/ \mathrm{cm}^{2}$ increases very significantly with annealing time.

We have seen that the defect bands formed by high dose/ high energy and low dose/low energy implants evolve in dramatically different ways. In the high-dose/high energy 

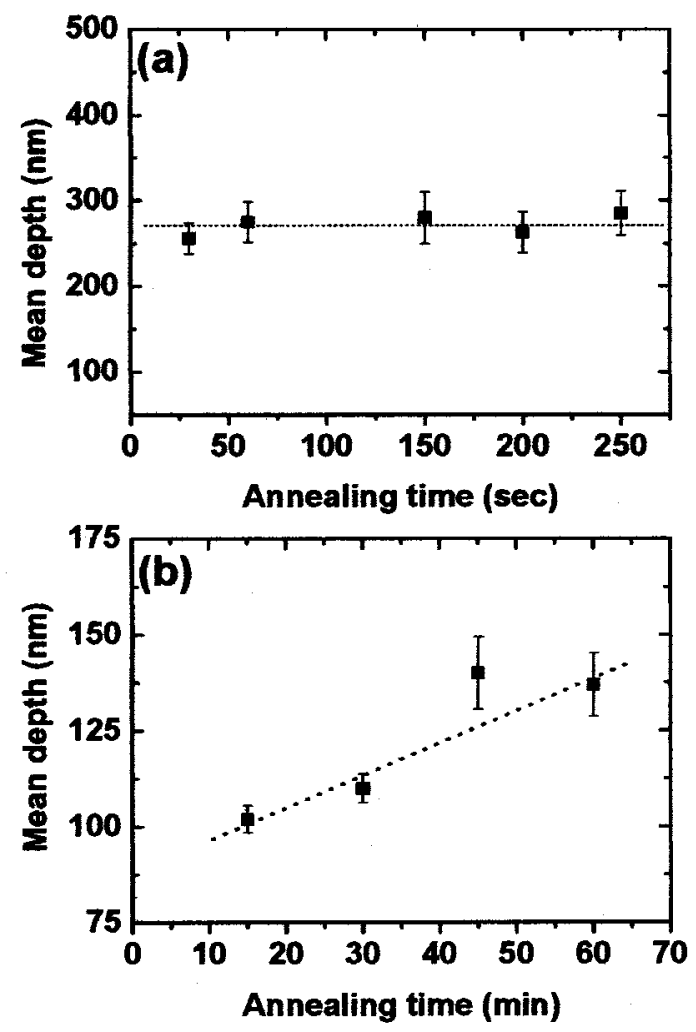

FIG. 4. Time evolution of the mean depth of the defects formed by (a) 100 $\mathrm{keV} 2 \times 10^{14} \mathrm{~cm}^{-2} \mathrm{Si}$ implant annealed at $850^{\circ} \mathrm{C}$ and (b) $40 \mathrm{keV} 6$ $\times 10^{13} \mathrm{~cm}^{-2} \mathrm{Si}$ implant annealed at $740^{\circ} \mathrm{C}$. In (a) the data are consistent with no changes in the mean depth. In (b) the mean depth increases with time. The dotted line is the best straight-line fit to the experimental results.

case, the defect band shows no sign of dissolution during the $\{113\}$ dominated phase, and subsequent transformation of the $\{113\}$ defects into loops produces a very stable defect population that will survive very long annealing times without significant dissolution. In the low dose/low energy case, the ripening of the $\{113\}$ defects is accompanied by rapid dissolution of the defect band, so that the defects never become large enough to transform into loops.

The reason for the rapid dissolution in the low dose/low energy case is evident from the way in which the band dissolves. Dissolution occurs first on the near-surface side of the defect band, and only later do the deeper defects start to dissolve as well. The rapid dissolution is evidently a consequence of the proximity of the silicon surface, which is a sink for interstitials escaping from the defect band. The absence of dissolution on the deep side of the band shows that interstitials escaping into deeper regions of the silicon encounter few significant sinks, and most of them simply return to the band to be reincorporated within extended defects. These results perfectly support the view that the surface is the ultimate sink for interstitials escaping from the defect region.

The reason that no significant dissolution is observed on the surface side of the band for the high-dose implant is that the defect density is higher, and the distance to the surface is larger than in the earlier case. A higher defect density means that it will take longer for a given flux of interstitials to deplete the layer, and the greater depth reduces the gradient, and thus the flux, of interstitials diffusing from the band towards the surface. Before enough interstitials can escape from the band to the surface to produce an observable depletion in the near-surface side of the band, the defects have already ripened and transformed into loops, leading to a collapse in the interstitial supersaturation, and thus a further huge reduction in the flux of interstitials towards the surface. This does not mean that the band is completely immune to dissolution. What happens is that the time scale for dissolution of the band is increased by several orders of magnitude due to the much greater stability of dislocation loops with respect to dissolution. TED extractions, ${ }^{7}$ show that even in the high-dose case, the defect band actually does lose some interstitials to the surface. The TED experiments show that the supersaturation of $\mathrm{Si}$ interstitials decreases linearly between the defect band and the surface, indicating a flux of interstitials from the band to the surface, as expected.

Clearly our results are in direct contradiction to the conclusion of Moller et al., ${ }^{5}$ who found that the defect band does not dissolve preferentially at the surface side. However, the reliability of their result is significantly limited by the fact that they did not measure quantitative depth distributions, but only qualitative estimates of the depth of the top and bottom of the defect band. Such estimates are poorly defined and unreliable, since the defect band does not have well defined edges, see for example Fig. 2. Indeed, only by measuring depth distributions is it possible properly to observe and quantify the shift in the defect profile.

In summary, we have shown that the key factor in the defect evolution is nonconservative Ostwald ripening in the presence of an external sink, clearly identified as the silicon surface. The dissolution appears as a loss of defects on the near-surface side of the defect band, as one would expect when the interstitial supersaturation decreases towards the surface. Finally, our quantitative data on the $\{113\}$ defect density as a function of depth and annealing time will enable improvement and testing of physical models of defect evolution and TED.

This work is part of the IST/FRENDTECH project (IST Project No. 2000-30129), and has been supported with an equipment grant from the UK Royal Academy of Engineering.

${ }^{1}$ D. Lim, C. Rafferty and F. Klemens, Appl. Phys. Lett. 67, 2302 (1995).

${ }^{2}$ A. H. Gencer and S. T. Dunham, J. Appl. Phys. 81, 631 (1997).

${ }^{3}$ L. Pelaz, G. H. Gilmer, V. C. Venezia, H.-J. Gossmann, M. Jaraiz, and J. Barbolla, Appl. Phys. Lett. 74, 2017 (1999).

${ }^{4}$ B. Colombeau, F. Cristiano, A. Altibelli, C. Bonafos, G. B. Assayag, and A. Claverie, Appl. Phys. Lett. 78, 940 (2001).

${ }^{5}$ K. Moller, K. Jones, and M. Law, Appl. Phys. Lett. 72, 2547 (1998).

${ }^{6}$ A. Claverie, B. Colombeau, G. Ben Assayag, C. Bonafos, F. Cristiano, M. Omri, and B. de Mauduit, Mater. Sci. Semicond. Process. 3, 269 (2000).

${ }^{7}$ F. Cristiano, Y. Lamrani, B. Colombeau, P. Calvo, and A. Claverie (unpublished). 